\title{
The research about radiometric technology of two-dimensional rotary table based on image gray level
}

\author{
Xiangyao Xue ${ }^{1}$, Chunxiang Liu', Jian Qiao², Wenbao Zhang ${ }^{1}$ and Ning $\mathrm{Li}^{\mathrm{i}^{*}}$
}

\begin{abstract}
It is difficult to measure infrared radiation quantitatively for fast dynamic targets such as aircraft and missile. At present, there are many problems such as low measurement accuracy, feedback delay, and complex measurement system. In this paper, a radiation measurement scheme based on image grayscale is proposed. The scheme adopts a two-dimensional turntable structure, which can measure the radiation quantity rapidly and accurately. Based on the image method, this method is used to calibrate the gray value of the target point and compare it with that of the absolute standard radiator, so as to obtain the radiation value of the target indirectly. The key of this method is to establish an accurate radiation measurement model. The proposed model based on dynamic calibration is about $50 \%$ more accurate than the traditional model. The final measurement accuracy of this model is $75 \%$. Through the infrared radiation measurement of specific dynamic objects in two-dimensional space, it is found that the dynamic calibration model based on this measurement method has higher measurement precision.
\end{abstract}

Keywords: Image processing, Image grayscale, Two-dimensional turntable, Radiation measurement, Measurement model, Dynamic calibration

\section{Introduction}

Traditional infrared radiation measurement mainly includes two kinds, one is direct measurement based on temperature and wavelength, the other is indirect measurement based on image. The results of direct measurement are relatively accurate, but it is impossible to realize the rapid measurement of remote targets, and the equipment required for direct measurement is relatively complex [1]. Therefore, the research in the field of infrared radiation measurement mainly focuses on indirect measurement. The accuracy of indirect infrared radiation measurement is affected by many factors. Accurate calibration of measuring equipment is required to obtain accurate measurement values. This calibration requires an accurate calculation model, and the establishment of the model is closely related to the idea of the model, the environmental condition of the measurement area and the time of measurement [2-11]. Material motion is the

\footnotetext{
* Correspondence: smallpotato1982@126.com

${ }^{1}$ Changchun Institute of Optics, Fine Mechanics and Physics, Chinese

Academy of Science, Changchun 130033, Jilin, China

Full list of author information is available at the end of the article
}

source of infrared thermal radiation. The size of infrared thermal radiation is mainly affected by the temperature of the object and the nature of the material itself. Describing thermal radiation requires some commonly used basic quantities. Thermal radiation has both the general law of electromagnetic waves and the particularity of its radiation. Therefore, in order to better describe the measurement technology of infrared radiation characteristics, we should first master the basic metrics describing infrared radiation. The radiation calibration of infrared radiation measurement system based on image is the basis of the measurement of infrared radiation characteristics. The purpose of radiation calibration is to obtain its own response parameters including the response rate and its own bias response, so as to establish a quantitative relationship between the radiation output of the radiation source and the digital output gray value of the infrared radiation measurement system. At present, in the field of measurement, the common radiation calibration methods of image-based infrared radiation measurement system mainly include close-range standard extended source image calibration method and 
high-temperature cavity type black body parallel optical tube calibration method.

The close-range standard extended source calibration method is one of the most common calibration methods in the field of ground shooting ranges. It mainly uses the high-emissivity and well-uniformed facial source black body as the standard extended calibration source, and places the facial source black body in the infrared radiation measurement system. Into the pupil, the effective radiation surface of the face source black body completely covers the entrance pupil of the system. In spite of this, there are also shortcomings in the application of the close-range standard extension source calibration method in the outer field. For example, as the caliber of the modern shooting range gradually increases with the infrared radiation measurement system, a standard extension source with large surface source size is required, and the difficulty of processing is greatly increased. The design and manufacturing threshold of large source extension source is high, which causes the cost of radiation calibration to increase dramatically. More seriously, the standard extension source of large surface size is difficult to rise to high temperature and maintain a uniform temperature, so that it cannot be established. The high-temperature calibration of the infrared radiation characteristic measurement system is presented. The high-temperature cavity-type black body parallel optical tube calibration method is to place the high-temperature cavity-type black body at the image surface of the large-diameter parallel optical tube to achieve a uniform expansion of the fine beam high-temperature cavity black body and to achieve a high-temperature radiation calibration in the infrared radiation measurement system. The infrared radiation measurement system is usually close to the entrance pupil of the parallel optical tube, and the parallel beam is projected into the infrared radiation measurement system after the beam is expanded, so as to achieve the calibration of the infrared radiation measurement system. Unlike the critical lighting calibration of the close-range extension source, the method is essentially uniform imaging by emitting light from the high-temperature cavity-type black body. Infrared radiation characteristic measurement technology, as an important part of improving the national defense informationization equipment system, can provide quantitative measurement data for the performance of the equipment. Therefore, the world's military powers have always attached great importance to the development of radiation characteristic measurement techniques. Military powers such as Europe and the USA have successively established a radiation characteristic measurement system covering a wide band from ultraviolet to long-wave infrared, and vertically covers foundations, airborne (airborne, spherical), and on-orbit space-based (space-borne) radiation characteristics measurement systems. Nowadays, the construction of radiation characteristic measurement system has been basically completed, and an in-depth study has been made to improve the accuracy of the database. This paper presents a method for indirect infrared radiation measurement of targets in half-space field of view. The most important research content of this method is the inversion calibration model of infrared radiation. In this paper, the traditional inversion model is improved under the background of dynamic target measurement, and the experimental method is used to verify it, and a relatively accurate calibration model is obtained for dynamic target infrared radiation measurement.

\section{Dynamic radiation measurement based on gray image}

The dynamic target radiation measurement based on gray image is different from the traditional direct radiation calibration principle. The radiation model of this principle is as follows.

The operating temperature of the radiation source is assumed to be $T$. The output spectral radiance is $L_{\lambda}$, ${ }_{s}(T)$. The output digital value obtained from the infrared measurement equipment to the radiation source is DN. The relationship between input radiance and output digital value of the measuring equipment is as follows:

$$
\mathrm{DN}=\alpha \int_{\lambda_{1}}^{\lambda_{2}} R_{\lambda}\left[L_{\lambda, s}(T)+L_{\lambda, \mathrm{bg}}\left(T^{\prime}\right)\right] d \lambda
$$

$\alpha$ is the absolute radiance response of the equipment to be calibrated, $R_{\lambda}$ is the spectral response function of calibrated measuring equipment, $L_{\lambda}$, bg $(T)$ is the background radiation including the radiation of the measuring equipment itself.

For the equipment calibration based on the surface source gray body, the formula for calculating the spectral radiance of the source is as follows:

$$
L_{\lambda, s}(T)=\frac{\varepsilon_{\mathrm{bb}}}{\pi} C_{1} \lambda^{-5}\left(e^{\frac{C_{2}}{\lambda T}}-1\right)^{-1}
$$

$\varepsilon_{\mathrm{bb}}$ is the transmittance of gray body, $C_{1}$ and $C_{2}$ are the first and second radiation constants respectively.

For calibration of equipment based on the combination of cavity gray body and parallel light pipe, the spectral radiance of the radiation source is as follows:

$$
L_{\lambda, s}(T)=\tau_{c} \frac{\varepsilon_{\lambda \mathrm{bb}}}{\pi} C_{1} \lambda^{-5}\left(e^{\frac{C_{2}}{T T}}-1\right)^{-1}
$$

$\tau_{c}$ is the transmittance of parallel light pipe.

$$
\text { Make } L_{s}=\int_{\lambda_{1}}^{\lambda_{2}} R_{\lambda} \cdot L_{\lambda, s}(T) d \lambda, L_{b g}=\int_{\lambda_{1}}^{\lambda_{2}} R_{\lambda} \cdot L_{\lambda, \mathrm{bg}}\left(T^{\prime}\right) d \lambda
$$

, thus formula (3) is changed to the next. 


$$
\mathrm{DN}=\alpha L_{s}+\alpha L_{\mathrm{bg}}
$$

Change the operating temperature of the radiation source $T$. Obtain multiple device input radiance $L_{s, i}$ and corresponding output value $\mathrm{DN}_{i}$. According to Eq. (4), $L_{s, i}$ and $\mathrm{DN}_{i}$ by linear fitting, the absolute radiance response of the device is obtained $\alpha$.

$D N_{0}=\alpha \cdot L_{\mathrm{bg}}$, radiometric displacement of a device called an infrared measurement device.

Spectral scaling based on image grayscale. The principle of spectral calibration is basically the same as that of upper section radiation calibration. The spectral calibration model of infrared measuring equipment is as follows:

$$
\mathrm{DN}_{\Delta \lambda}=r_{\lambda_{0}} \int_{\lambda_{0}-\Delta \lambda / 2}^{\lambda_{0}+\Delta \lambda / 2}\left[L_{\lambda, s}(T)+L_{\lambda, \mathrm{bg}}\left(T^{\prime}\right)\right] d \lambda
$$

$r_{\lambda_{0}}$ measures the response of the equipment. $L_{\lambda, s}(T)$ spectral radiance of an infrared radiation source (an infrared monochromatic light tube). $L_{\lambda \text {, bg }}(T)$ is the background radiation.

Change the operating temperature of the radiation source, obtain multiple sets of input radiance and corresponding output values, and perform linear fitting according to Eq. (5) to obtain the response degree of the infrared measuring equipment at the wavelength $r_{\lambda_{0}}$.

Change the working wavelength of the monochrome lighting tube and repeat the above steps to obtain the response of the measuring equipment at each wavelength. $r_{\lambda_{p}}$ spectral response function of the device is obtained by normalization of maximum value:

$$
R_{\lambda}=\frac{r_{\lambda}}{r_{\lambda_{p}}}
$$

Accuracy model of radiometric calibration. First, the accuracy of spectral calibration of infrared measuring equipment is analyzed. According to spectral scaling formula (5):

$$
\mathrm{DN}_{\Delta \lambda}=r_{\lambda_{0}} \int_{\lambda_{0}-\Delta \lambda / 2}^{\lambda_{0}+\Delta \lambda / 2}\left[L_{\lambda, s}(T)+L_{\lambda, \mathrm{bg}}\left(T^{\prime}\right)\right] d \lambda
$$

Relative spectral responsiveness of infrared measurement equipment $R_{\lambda}\left(r_{\lambda}\right)$ uncertainty depends on the output value of the device $\mathrm{DN}_{\Delta \lambda}$. Infrared monochrome light tube

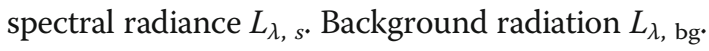

1) Under the current technology level of infrared imaging and digital signal processing, the uncertainty $\boldsymbol{D} \boldsymbol{N}_{\Delta \lambda}$ is superior of $2 \%$;

2) $L_{\lambda, s}$ is necessary to use the infrared radiometer for measurement. The uncertainty depends on the measurement accuracy of the infrared radiometer and the non-uniformity of the lighting tube $4 \% . L_{\lambda, s}$ uncertainty is $2.8 \%$
3) $\pm 1{ }^{\circ} \mathrm{C}$ background radiation due to changes in

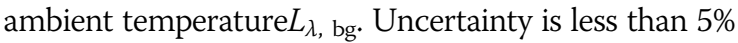

According to the above analysis, the uncertainty of relative spectral response is superior of $5.5 \%$

The accuracy of radiometric calibration of infrared measuring equipment is analyzed as follows. According to the radiation calibration formula (7)

$$
\mathrm{DN}=\alpha \int_{\lambda_{1}}^{\lambda_{2}} R_{\lambda}\left[L_{\lambda, s}(T)+L_{\lambda, \mathrm{bg}}\left(T^{\prime}\right)\right] d \lambda
$$

The uncertainty of the absolute radiance response of the equipment depends on the output value of the equipment, the spectral radiance of the radiation source, the relative spectral response of the equipment, and the background radiation $L_{\lambda \text {, bg. }}$.

1) Uncertainty is better than $1 \%$;

2) Under the current level of gray system, the spectral radiance uncertainty of gray body is better than $2 \%$;

3) Uncertainty of relative spectral response of equipment is better than 3.6\%;

4) Background radiation uncertainty is $2 \%$.

According to the above analysis, the uncertainty of the absolute radiofrequency response of the device is better than $4.7 \%$.

\section{Method-design of infrared radiation measurement model based on dynamic calibration}

According to specific dynamic target infrared radiation measurement requirements, the above measurement model is improved. The calibration and data processing system involved in the model is composed of calibration equipment, atmospheric correction equipment, and target characteristics data processing equipment. The system mainly completes the radiation calibration of the infrared measurement equipment and the inversion processing of the target measurement data, and finally obtains the infrared radiation characteristics of the target.

\subsection{Conditions and methods for establishing the radiation measurement model}

Indirect-type infrared radiation calibration equipment including high-temperature chamber gray body, low-temperature diffuse gray body, parallel light tube, infrared radiometer, and calibration data processing equipment such as computer, used in the infrared measurement equipment in the laboratory radiation calibration, determine the infrared radiation of input and output signal of the measuring device, the radiation response of the relationship between the radiation 


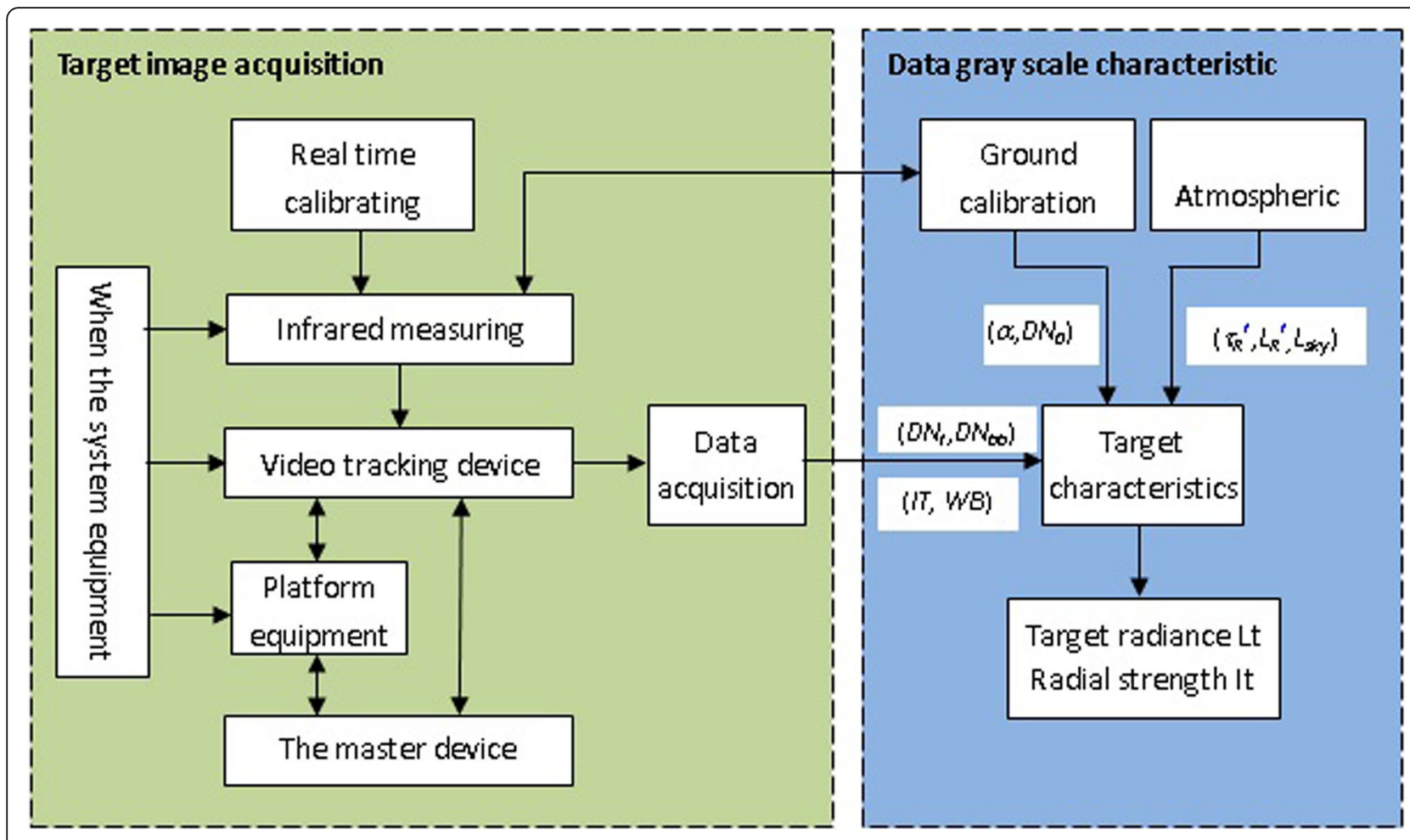

Fig. 1 Schematic diagram of the model

response. Atmospheric correction equipment includes micro-pulse lidar, temperature-humidity instrument, and atmospheric radiation transmission calculation software, which are used to measure atmospheric parameters and calculate the atmospheric transmittance and range radiation between the target and the infrared measurement equipment according to atmospheric parameters and target position information. The calibration equipment mainly includes the surface source gray body and the infrared paint reference plate, which is used to calibrate the atmospheric transmittance between the target and the infrared measurement equipment in real time. The target characteristics data processing equipment USES the radiation response of the infrared measurement equipment, atmospheric transmittance between the target and the infrared measurement equipment and other data to calculate the infrared radiation characteristics of the target from the target measurement data, such as the target radiance and radiation intensity.

The most important function of the infrared characteristics measurement system based on image grayscale is to measure the infrared radiation characteristics of the target $[2,3,12-20]$. The operating principle of the system is shown in Fig. 1.

In Fig. 1, the symbols in the data processing block diagram of the target characteristics are as follows: $\alpha$-infrared radiation response measuring equipment;

$\mathrm{DN}_{0}-$ calibration deviation of $\mathrm{dn} 0$-infrared measuring equipment;

$\tau_{R}{ }^{\prime}$ - target aircraft and the atmospheric transmittance between infrared measuring equipment;

$L_{R}{ }^{\prime}-$ target aircraft and infrared measuring equipment between atmospheric path radiation;

$L_{\text {sky }}-$ Lsky-measured sky background brightness;

$\mathrm{DN}_{t}$-infrared measurement equipment to the target;

$\mathrm{DN}_{\mathrm{bb}}$ - measured value of the standard calibration gray body (or the infrared paint pod) of the dnbb-infrared measuring equipment;

IT_-infrared measuring equipment integral time;

WB-infrared measuring equipment working band.

Table 1 Parameters of the test system detector

\begin{tabular}{ll}
\hline Working band & $3.7 \mu \mathrm{m} \sim 4.8 \mu \mathrm{m}$ \\
\hline Detector type & $\mathrm{HgCdTe}$ \\
Target surface size & $640 \times 512$ \\
Like size & $15 \mu \mathrm{m} \times 15 \mu \mathrm{m}$ \\
Cold screen number $\mathrm{F}$ & $\mathrm{F} 2$ \\
Frame frequency & $50 \mathrm{~Hz}$ \\
Interface form & CameraLink \\
NETD@22 ${ }^{\circ} \mathrm{C}$ & $18 \mathrm{mK}$ \\
Cooling way & Stirling refrigeration
\end{tabular}




\section{Spectral Response}

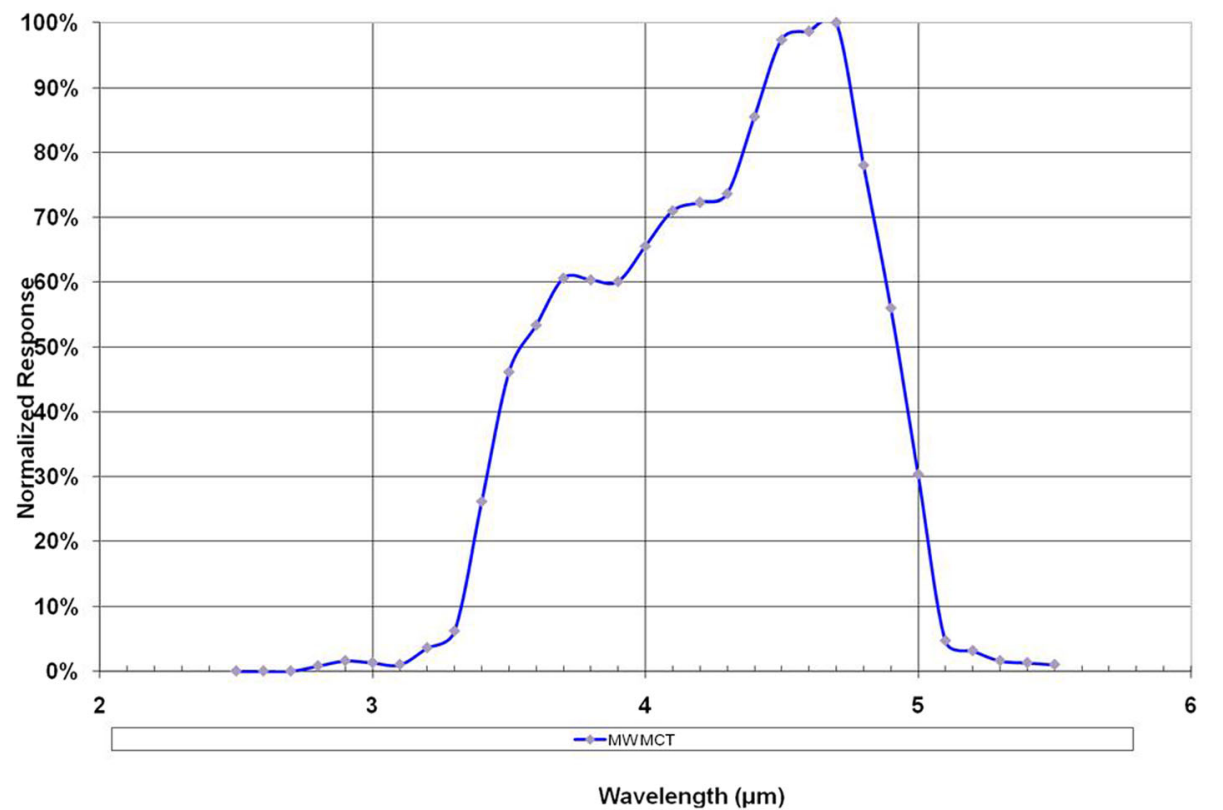

Fig. 2 Spectral response curve of medium wave detector

The measurement of infrared characteristics based on image grayscale includes two tasks: first, acquisition of target information and acquisition of target infrared digital image information. The second is the data processing of the target characteristics.

The process of target information acquisition is as follows:

Step 1: get the infrared image of the surface source gray body. The two-dimensional infrared measurement rotary table equipment can capture the target according to the guidance information, and then the servo tracking equipment can achieve precise tracking and measurement of the target through reasonable tracking means, and obtain the gray level of the surface source gray body (or the infrared image gray level) and transmit it to the data acquisition and transmission equipment.

Step 2: acquire the target infrared image. The image grayscale is transmitted to the data acquisition and transmission equipment.

Step 3: import the gray image index of the two into the calculation model, get the relationship curve between the gray value and infrared radiation value under specific target and specific condition, and invert the required target radiation value according to the curve.

The data processing process of the target features is as follows:

First, calibration equipment of infrared measuring equipment is used to calibrate the radiation and

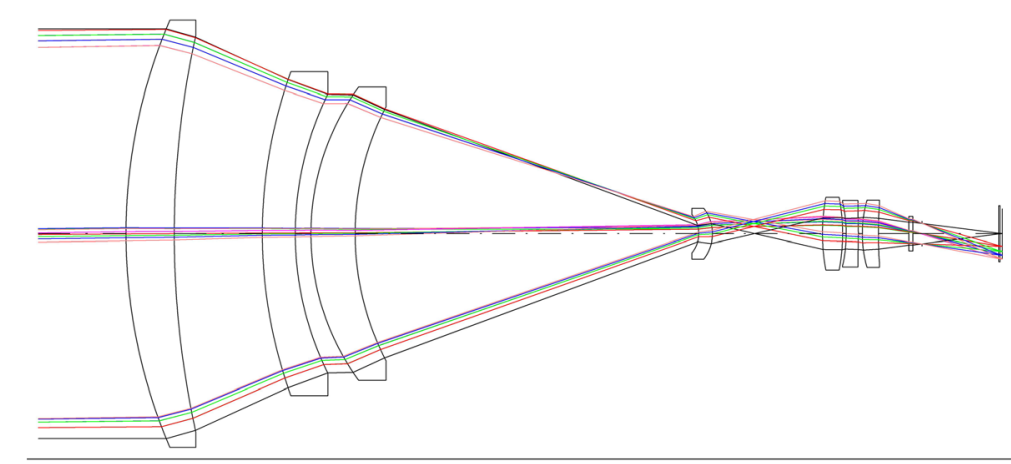

Fig. 3 Optical system diagram of the test system 
determine the degree of infrared radiation response of the measuring equipment offset $\mathrm{DN}_{0} \alpha$ and calibration. By the target information acquisition process, infrared measuring equipment first obtain $\mathrm{HO}$ height, horizontal distance $R 0$ of non-point source gray body infrared image, thus calculate the distance measured atmospheric transmittance of $R 0 L_{\mathrm{R} 0}, R 0$, and Cheng radiation. At the same time, a laser radar, the temperature and humidity meter atmospheric measurement equipment, was used so as to obtain highly $H_{0}$ Ta aerosol extinction coefficient, temperature, and relative humidity $\mathrm{RH}$, parameters, such as the provided MODTRAN software calculation theory of atmospheric transmittance $R 0$ and theoretical path radiation $L_{\mathrm{R} 0}$. As a result, get the atmospheric transmittance correction coefficient $C=R 0$, routine radiation correction coefficient $C \mathrm{p}=L_{\mathrm{R} 0} / L_{\mathrm{R} 0}$.

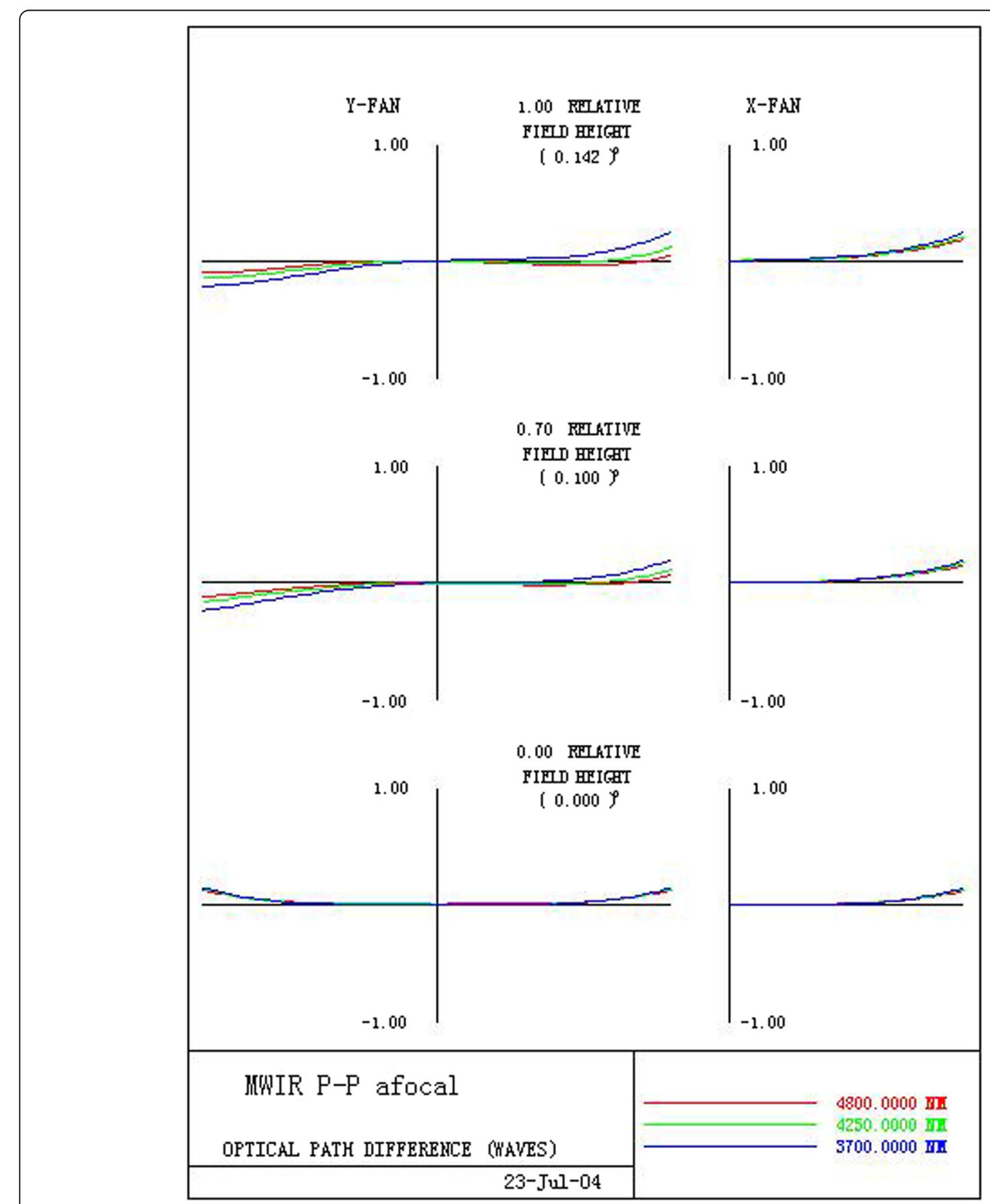

Fig. 4 System aberration curve diagram 

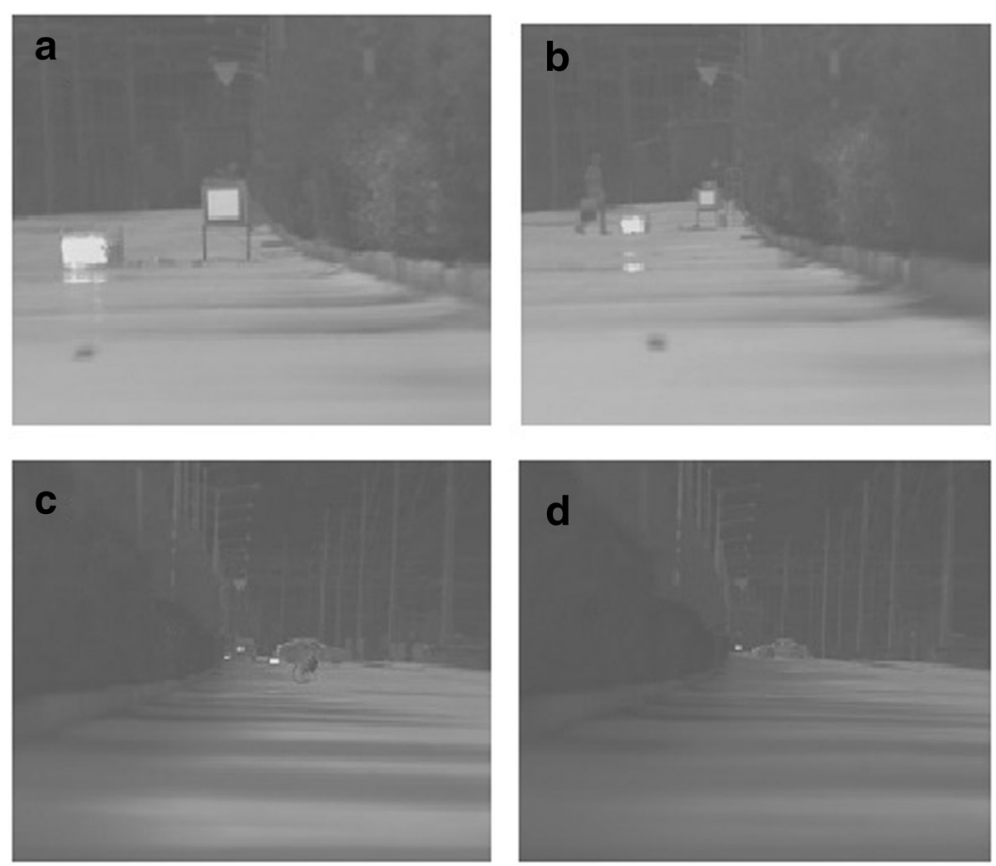

Fig. 5 Grayscale of field test

Then, the infrared characteristic of the target of distance $R$ is measured, and the infrared image of the target aircraft is obtained. Ta, RH, and according to the atmospheric parameters, by using MODTRAN software to calculate the distance $R$ theory of atmospheric transmittance $R$ routine radiation LR and theory, and then multiplied by the transmittance correction coefficient $C$ respectively and routine radiation correction coefficient $C \mathrm{p}$, after correction of atmospheric transmittance $L R * R *$ and radiation.

Finally, using the infrared radiation response of measurement equipment, calibration after atmospheric transmittance $L R^{*} R$ and Cheng radiation, the gray value is measured by the target infrared radiation characteristics of inverse calculation target aircraft, such as radial brightness and radiant intensity.

\subsection{The calibration model of infrared radiation} measurement based on image grayscale is designed Based on the calibration theory of infrared coating radiation measurement model, the model based on infrared target image is improved:

Table 2 Calibration results of FLIR mid-wave infrared camera

\begin{tabular}{llll}
$\begin{array}{l}\text { Integration } \\
\text { time }\end{array}$ & $\mathrm{IT}=0.5 \mathrm{~ms}$ & $\mathrm{IT}=1 \mathrm{~ms}$ & $\mathrm{IT}=2 \mathrm{~ms}$ \\
\hline $\begin{array}{l}\text { Calibration } \\
\text { results }\end{array}$ & $\mathrm{DN}=931 \mathrm{~L}+245$ & $\mathrm{DN}=1821 \mathrm{~L}+558$ & $\mathrm{DN}=3619 \mathrm{~L}+1068$ \\
\hline
\end{tabular}

$$
L_{t}=\frac{\left(\mathrm{DN}_{t}-\mathrm{DN}_{0}\right) / \alpha-\left(\frac{L_{R}{ }^{\prime}}{L_{R 0}{ }^{\prime}} L_{R 0} \tau_{1}+L_{1}\right)}{\frac{\tau_{R}^{\prime}}{\tau_{R 0}{ }^{\prime}} \tau_{R 0} \tau_{1}}
$$

From the above equation, $L_{t}$ measurement accuracy depends on $\mathrm{DN}_{t}, \mathrm{DN}_{0}, \alpha, \tau_{R 0}, L_{R 0}, \frac{\tau_{R}{ }^{\prime}}{\tau_{R 0}{ }^{\prime}}, \frac{L_{R}{ }^{\prime}}{L_{R 0}}, \tau_{1}$, and $L_{1}$. The above uncertainty parameters are analyzed as follows: target measurement output value $\mathrm{DN}_{t}$ is better than $1 \%$. The radiance response of infrared equipment $\mathrm{DN}_{0}$ is better than $4.7 \%$. Measured atmospheric transmittance based on infrared targets $\tau_{R 0}$ uncertainty is $10.5 \%$. The uncertainty of measured atmospheric path radiation based on infrared target is set at $12 \%$., uncertainty is about $4.1 \%$. The uncertainty of transmittance ratio and radiation ratio is $3.5 \%$. According to the above analysis, the accuracy of the infrared target inversion method is $49 \%$. Compared with the traditional measurement model, the accuracy of the model is improved by $50 \%$.

Table 3 Measurement results of gray bodies at different temperatures at a distance of $100 \mathrm{~m}$

\begin{tabular}{|c|c|c|c|c|c|}
\hline \multirow{2}{*}{$\begin{array}{l}\text { The target } \\
\text { distance }\end{array}$} & \multirow{2}{*}{$\begin{array}{l}\text { The target } \\
\text { temperature }\left({ }^{\circ} \mathrm{C}\right)\end{array}$} & \multirow{2}{*}{$\begin{array}{l}\text { Target } \\
\text { radiance }\end{array}$} & \multicolumn{3}{|c|}{ Target measurement } \\
\hline & & & $\mathrm{IT}=0.5 \mathrm{~ms}$ & $\mathrm{IT}=1 \mathrm{~ms}$ & $\mathrm{IT}=2 \mathrm{~ms}$ \\
\hline \multirow[t]{4}{*}{$100 \mathrm{~m}$} & 45 & 1.926 & 2090 & 4150 & 8224 \\
\hline & 50 & 2.671 & 2618 & 5182 & 10,242 \\
\hline & 60 & 3.633 & 3296 & 6518 & 12,936 \\
\hline & 65 & 4.209 & 3694 & 7319 & \\
\hline
\end{tabular}




\section{Radiation measurement results and discussions based on image grayscale}

In order to verify the accuracy of the above model based on image gray level inversion calibration with higher measurement accuracy, related experiments are carried out in this paper.

\subsection{The test methods and procedures}

The test procedure is as follows:

In the laboratory using the infrared camera gray body radiation calibration, determine the camera radiation responsivity $\alpha$ and offset DNO;

In the external field, an infrared camera is used to measure the surface source gray body at a distance of $R 0$ to obtain the measured atmospheric transmittance and atmospheric radiation.

During the measurement period, the ground horizontal visibility Vis was obtained by using lidar, and the air temperature Ta and relative humidity $\mathrm{RH}$ were obtained by using temperature and humidity meter. According to these parameters, the theoretical atmospheric transmittance and path radiation between infrared camera and gray body were calculated by using MODTRAN software.

Calculation of atmospheric transmittance correction coefficient and range radiation correction coefficient.

The gray body was placed in the distance infrared camera $(R)$, and the gray body was measured with the infrared camera to obtain the infrared image of the distance $R$.

According to distance $R$, the theoretical atmospheric transmittance and path radiation between the mid-wave infrared camera and the gray body were calculated by using MODTRAN software, and the corrected transmittance and path radiation were obtained by multiplying the correction coefficient respectively.

Based on the radiation response of infrared camera degree $\alpha$ and offset $\mathrm{DN}_{0}$, respectively, using the theory of atmospheric transmittance and routine radiation and the atmospheric transmittance and routine radiation after correction, the inversion of the gray body radial brightness, calculate the inversion error.

The experimental measurement system adopted is based on mid-wave infrared, which adopts the MW MimiCore HRC detector of FLIR company. The parameters, shape, and response curves of the detector are shown in Table 1:

The spectral curve of the detector of the grayscale infrared radiation measurement system is shown in Fig. 2.

Table 4 Measured atmospheric transmittance at a distance of $100 \mathrm{~m}$

\begin{tabular}{lccc}
\hline The measured distance $(\mathrm{m})$ & $\mathrm{IT}=0.5 \mathrm{~ms}$ & $\mathrm{IT}=1 \mathrm{~ms}$ & $\mathrm{IT}=2 \mathrm{~ms}$ \\
\hline 100 & 0.756 & 0.762 & 0.763 \\
\hline
\end{tabular}

Table 5 Theoretical atmospheric transmittance at various distances calculated by MODTRAN

\begin{tabular}{ll}
\hline The measured distance $(\mathrm{m})$ & MODTRAN transmittance $\tau_{a}{ }^{\prime}$ \\
\hline 200 & 0.762 \\
300 & 0.741 \\
400 & 0.719 \\
\hline
\end{tabular}

The optical system adopted by the measurement system is a transmission optical system, and its main technical indicators are as follows:

- Mouth diameter: $80 \mathrm{~mm}$;

- Focal distance: $f=160 \mathrm{~mm}$;

- Visual field: $3.4^{\circ} \times 2.7^{\circ}$.

The advantages of the system are large field of view and good image quality. The aspherical transmission mirror can ensure good imaging quality in the larger field of view. The optical mechanical structure of the optical system is shown in Fig. 3.

For the characteristic frequency of $16 \mathrm{lp} / \mathrm{mm}$, the diffraction limit is reached on the transfer function number axis of the optical system, the diffraction limit is nearly reached outside the axis, and the system distortion is less than $1 \%$. The system aberration curve of the test system is shown in Fig. 4.

\subsection{Experiment and analysis based on image grayscale}

In 2018, using FLIR mid-wave infrared camera and ISDC face source gray body, the project team carried out field test of radiation measurement method based on calibrated gray body on a road with few pedestrians. The FLIR camera measures the gray body images of different distances as shown in Fig. 5. In this figure, a is the 100 $\mathrm{m}$ gray body measurement image, $\mathrm{b}$ is the $200 \mathrm{~m}$ gray body measurement image, $\mathrm{c}$ is the $300 \mathrm{~m}$ gray body measurement image, and $\mathrm{d}$ is the $400 \mathrm{~m}$ gray body measurement image.

The grayscale radiation results of laboratory images of the FLIR mid-wave infrared camera are shown in Table 2.

Table 3 shows the measurement results of the FLIR medium wave camera at different temperatures of $100 \mathrm{~m}$ in different integral time.

Table 6 Corrected atmospheric transmittance

\begin{tabular}{llll}
\hline $\begin{array}{l}\text { The measured } \\
\text { distance }(\mathrm{m})\end{array}$ & \multicolumn{4}{l}{ Corrected transmittance $\mathrm{\tau}_{\mathrm{a}}{ }^{*}$} \\
\cline { 2 - 4 } & $0.5 \mathrm{~ms}$ & $1 \mathrm{~ms}$ & $2 \mathrm{~ms}$ \\
\hline 200 & 0.725 & 0.732 & 0.732 \\
300 & 0.705 & 0.711 & 0.712 \\
400 & 0.684 & 0.690 & 0.691 \\
\hline
\end{tabular}


Table 7 Inversion results of atmospheric transmittance after modification when IT $=0.5 \mathrm{~ms}$

\begin{tabular}{|c|c|c|c|c|c|c|c|c|c|}
\hline \multirow[t]{2}{*}{$\begin{array}{l}\text { The target } \\
\text { distance }\end{array}$} & \multicolumn{2}{|c|}{$\begin{array}{l}\text { Atmospheric } \\
\text { transmittance }\end{array}$} & \multirow[t]{2}{*}{$\begin{array}{l}\text { The target } \\
\text { temperature }\left({ }^{\circ} \mathrm{C}\right)\end{array}$} & \multirow[t]{2}{*}{$\begin{array}{l}\text { Target } \\
\text { measurement }\end{array}$} & \multirow[t]{2}{*}{$\begin{array}{l}\text { Target } \\
\text { radiance }\end{array}$} & \multicolumn{2}{|l|}{ Inverse radiance } & \multicolumn{2}{|c|}{ The inversion error } \\
\hline & MODTRAN & $\begin{array}{l}\text { Corrected } \\
\text { transmittance }\end{array}$ & & & & $\begin{array}{l}\text { MODTRAN } \\
\text { inversion } \\
\text { radial brightness }\end{array}$ & $\begin{array}{l}\text { Corrected } \\
\text { inversion } \\
\text { radial brightness }\end{array}$ & $\begin{array}{l}\text { MODTRAN } \\
\text { inversion } \\
\text { error (\%) }\end{array}$ & $\begin{array}{l}\text { The revised } \\
\text { inversion } \\
\text { error (\%) }\end{array}$ \\
\hline \multirow[t]{4}{*}{$200 \mathrm{~m}$} & 0.872 & 0.826 & 44 & 2144 & 2.274 & 2.211 & 2.313 & 3.2 & 1.7 \\
\hline & & & 41 & 2471 & 2.771 & 2.729 & 2.773 & 1.7 & 3.4 \\
\hline & & & 71 & 3197 & 3.733 & 3.421 & 3.711 & 3.1 & 1.9 \\
\hline & & & 74 & 3479 & 4.219 & 4.147 & 4.274 & 3.7 & 1.3 \\
\hline \multirow[t]{4}{*}{$300 \mathrm{~m}$} & 0.832 & 0.806 & 44 & 2111 & 2.274 & 2.141 & 2.241 & 4.9 & 1.1 \\
\hline & & & 41 & 2342 & 2.771 & 2.491 & 2.719 & 7.7 & 2.1 \\
\hline & & & 71 & 2931 & 3.733 & 3.331 & 3.411 & 9.3 & 3.7 \\
\hline & & & 74 & 3274 & 4.219 & 3.931 & 4.127 & 9.1 & 4.3 \\
\hline \multirow[t]{4}{*}{$400 \mathrm{~m}$} & 0.829 & 0.783 & 44 & 2121 & 2.274 & 1.997 & 2.199 & 12.7 & 9.2 \\
\hline & & & 41 & 2243 & 2.771 & 2.337 & 2.444 & 12.4 & 9.1 \\
\hline & & & 71 & 2921 & 3.733 & 3.197 & 3.341 & 12.3 & 7.9 \\
\hline & & & 74 & 3173 & 4.219 & 3.711 & 3.999 & 12.1 & 7.7 \\
\hline
\end{tabular}

Table 4 shows the measured atmospheric transmittance at a distance of $100 \mathrm{~m}$ calculated from the measured value of the gray body.

MODTRAN software is used to calculate $100 \mathrm{~m}$ from the theory of atmospheric transmittance 0.794 ; using the theory of $80.5 \mathrm{~m}$ of the measured atmospheric transmittance and atmospheric transmittance, calculate the atmospheric transmittance correction coefficient.

$$
\begin{aligned}
& C_{\tau}=\tau_{a} / \tau_{a}{ }^{\prime}=0.756 / 0.794=0.952 \mathrm{IT}=0.5 \mathrm{~ms} \\
& C_{\tau}=\tau_{a} / \tau_{a}=0.762 / 0.794=0.960 \mathrm{IT}=1 \mathrm{~ms} \\
& C_{\tau}=\tau_{a} / \tau_{a}=0.763 / 0.794=0.961 \mathrm{IT}=2 \mathrm{~ms}
\end{aligned}
$$

The gray body is then measured at distances of $200 \mathrm{~m}$, $300 \mathrm{~m}$, and $400 \mathrm{~m}$ from the FLIR. By using MODTRAN software to calculate the distance of the theory of atmospheric transmittance ' $a$. The atmospheric transmittance calculated by the model is shown in Table 5 .

Using transmittance $C_{\mathrm{\tau}}$ correction coefficient $C$ of 200 $\mathrm{m}, 300 \mathrm{~m}$, and $400 \mathrm{~m}$ theory of atmospheric transmittance, $\tau_{\mathrm{a}}{ }^{*}=\tau_{\mathrm{a}}{ }^{\prime} \times C_{\mathrm{T}}$, as shown in Table 6 .

Then, using the theory of MODTRAN respectively atmospheric transmittance $\tau_{\mathrm{a}}{ }^{\prime} \mathrm{\tau}$ and revised the atmospheric transmittance $\tau_{\alpha}{ }^{*}$, to $200 \mathrm{~m}, 300 \mathrm{~m}$, and $400 \mathrm{~m}$ in

\begin{tabular}{|c|c|c|c|c|c|c|c|c|c|}
\hline \multirow{2}{*}{$\begin{array}{l}\text { The target } \\
\text { distance }\end{array}$} & \multicolumn{2}{|c|}{ Atmospheric transmittance } & \multirow{2}{*}{$\begin{array}{l}\text { The target } \\
\text { temperature }\left({ }^{\circ} \mathrm{C}\right)\end{array}$} & \multirow{2}{*}{$\begin{array}{l}\text { Target } \\
\text { measurement }\end{array}$} & \multirow{2}{*}{$\begin{array}{l}\text { Target } \\
\text { radiance }\end{array}$} & \multicolumn{2}{|c|}{ Inverse radiance } & \multicolumn{2}{|c|}{ The inversion error } \\
\hline & MODTRAN & $\begin{array}{l}\text { Corrected } \\
\text { transmittance }\end{array}$ & & & & $\begin{array}{l}\text { MODT } \\
\text { radial }\end{array}$ & $\begin{array}{l}\text { inversion } \\
\text { tness }\end{array}$ & MODTRAN (\%) & $\begin{array}{l}\text { Corrected } \\
\text { transmittance (\%) }\end{array}$ \\
\hline \multirow[t]{4}{*}{$200 \mathrm{~m}$} & 0.872 & 0.826 & 44 & 4211 & 2.264 & 2.184 & 2.284 & 2.4 & 1.4 \\
\hline & & & 41 & 4844 & 2.661 & 2.484 & 2.611 & 2.8 & 1 \\
\hline & & & 61 & 6111 & 2.622 & 2.411 & 2.642 & 2.6 & 1.2 \\
\hline & & & 64 & 6811 & 4.218 & 4.168 & 4.224 & 2.2 & 1.6 \\
\hline \multirow[t]{4}{*}{300 m } & 0.832 & 0.806 & 44 & 4146 & 2.264 & 2.184 & 2.162 & 8.4 & 4.4 \\
\hline & & & 41 & 4626 & 2.661 & 2.442 & 2.444 & 8.6 & 4.6 \\
\hline & & & 61 & 4668 & 2.622 & 2.288 & 2.428 & 8.2 & 4.4 \\
\hline & & & 64 & 6481 & 4.218 & 2.821 & 2.882 & 8.2 & 4.4 \\
\hline \multirow[t]{4}{*}{$400 \mathrm{~m}$} & 0.829 & 0.783 & 44 & 2848 & 2.264 & 1.844 & 2.126 & 14.4 & 11.8 \\
\hline & & & 41 & 4421 & 2.661 & 2.288 & 2.284 & 14.1 & 11.4 \\
\hline & & & 61 & 4444 & 2.622 & 2.164 & 2.286 & 12.8 & 8.2 \\
\hline & & & 64 & 6262 & 4.218 & 2.614 & 2.861 & 12.1 & 8.2 \\
\hline
\end{tabular}
gray body target measurements of radiation inversion.

Table 8 Inversion results of atmospheric transmittance after modification when IT = $1 \mathrm{~ms}$ 
Table 9 Inversion results of atmospheric transmittance after modification when IT = 2 ms

\begin{tabular}{|c|c|c|c|c|c|c|c|c|c|}
\hline \multirow{2}{*}{$\begin{array}{l}\text { The target } \\
\text { distance }\end{array}$} & \multicolumn{2}{|c|}{ Atmospheric transmittance } & \multirow{2}{*}{$\begin{array}{l}\text { The target } \\
\text { temperature }\left({ }^{\circ} \mathrm{C}\right)\end{array}$} & \multirow{2}{*}{$\begin{array}{l}\text { Target } \\
\text { measurement }\end{array}$} & \multirow{2}{*}{$\begin{array}{l}\text { Target } \\
\text { radiance }\end{array}$} & \multicolumn{2}{|c|}{$\begin{array}{l}\text { Inverse } \\
\text { radiance }\end{array}$} & \multicolumn{2}{|c|}{ The inversion error } \\
\hline & $\overline{\text { MODTRAN }}$ & $\begin{array}{l}\text { Corrected } \\
\text { transmittance }\end{array}$ & & & & $\begin{array}{l}\overline{\mathrm{MOD}} \\
\text { radial }\end{array}$ & $\begin{array}{l}\text { inversion } \\
\text { tness }\end{array}$ & $\overline{\text { MODTRAN (\%) }}$ & $\begin{array}{l}\text { Corrected } \\
\text { transmittance (\%) }\end{array}$ \\
\hline \multirow[t]{4}{*}{$200 \mathrm{~m}$} & 0.872 & 0.826 & 36 & 8379 & 2.283 & 2.280 & 2.279 & 3.2 & 0.2 \\
\hline & & & 60 & 9728 & 2.782 & 2.697 & 2.803 & 2.8 & 2.2 \\
\hline & & & 70 & 22,220 & 3.733 & 3.603 & 3.738 & 3.6 & 0.3 \\
\hline & & & 76 & 23,826 & 3.209 & 3.083 & 3.262 & 3.0 & 2 \\
\hline \multirow[t]{4}{*}{$300 m$} & 0.832 & 0.806 & 36 & 8297 & 2.283 & 2.083 & 2.279 & 8.3 & 3.7 \\
\hline & & & 60 & 9262 & 2.782 & 2.332 & 2.630 & 8.7 & 3.9 \\
\hline & & & 70 & 22,328 & 3.733 & 3.290 & 3.323 & 9.3 & 6.8 \\
\hline & & & 76 & 22,828 & 3.209 & 3.822 & 3.978 & 9.3 & 6.8 \\
\hline \multirow[t]{3}{*}{$400 \mathrm{~m}$} & 0.829 & 0.783 & 36 & 8838 & 2.283 & 2.967 & 2.033 & 23.0 & 20.6 \\
\hline & & & 60 & 8887 & 2.782 & 2.327 & 2.398 & 23.3 & 20.2 \\
\hline & & & 76 & 22,322 & 3.209 & 3.783 & 3.882 & 22.8 & 20.3 \\
\hline
\end{tabular}

As shown in Table 7 for IT $=0.5 \mathrm{~ms}$, the theory of MODTRAN atmospheric transmittance $\tau_{a}^{\prime}$ ' $T$ was used and the atmospheric transmittance $\tau_{\mathrm{a}}{ }^{*}$ in inversion results was revised.

The experiment USES different integral time of infrared camera to extract gray image. Table 8 shows the inversion results of MODTRAN atmospheric transmittance and modified atmospheric transmittance when $\mathrm{IT}=1 \mathrm{~ms}$.

Three kinds of integral time were used to measure this experiment, respectively, and reasonable selection was made according to the difference of grayscale and contrast. When IT $=2 \mathrm{~ms}$ is shown in Table 9, the inversion results of MODTRAN atmospheric transmittance and modified atmospheric transmittance are used.

It can be seen from the results of the measurement based on image grayscale calibration model of 2D turntable infrared radiation measurement inversion to correction of measurements, the inversion error as the measuring distance is magnified by the increasing trend, but the correction of the model through the inversion error is significantly lower, you can think of model calibration on the infrared radiation calibration of measuring device with high precision.

\section{Conclusion}

In this paper, the traditional indirect infrared radiation measurement model is improved, which is more suitable for remote dynamic target radiation measurement. In order to verify the accuracy of the model, a set of physical test system was established, and the model was validated by ground test. From the experimental results, the calibration model based on image grayscale has high accuracy in infrared radiation measurement, and its quantitative measurement accuracy is improved by about $50 \%$. Due to the limited conditions, the ground verification method is adopted in this test, and only the infrared radiation measurement of a single-direction target is verified in space. For the target selection, aircraft, missiles, and other quick maneuvering targets are not adopted, but the targets with slow movement are adopted. In the following research, it is necessary to improve these experiments and adopt more direct physical objects for measurement verification and model modification. At the same time, it is very necessary to analyze the environmental conditions in the follow-up study. The influence of atmospheric environment on radiation accuracy is very large, and the measurement accuracy of different atmospheric permeability, visibility, temperature, humidity, and other environments changes greatly. A more accurate measurement model can be obtained by fitting the refined experimental values under the above atmospheric conditions.

\section{Acknowledgements \\ The authors thank the editor and anonymous reviewers for their helpful comments and valuable suggestions.}

\section{Funding}

Not applicable.

Availability of data and materials

Please contact author for data requests.

\section{About the authors}

Xue Xiangyao received M. Sc and Ph. D from Changchun Institute of Optics, Fine Mechanics and Physics, Chinese Academy of Sciences, and is associate research fellow in Changchun Institute of Optics, Fine Mechanics and Physics, Chinese Academy of Sciences now. His main research interests include structure design of fine optical mechanics and image process. Liu Chunxiang was born in 1983, and graduated in Changchun Institute of Optics, Fine Mechanics and Physics, Chinese Academy of Sciences, and is associate research fellow in Changchun Institute of Optics, Fine Mechanics and Physics, Chinese Academy of Sciences now. Her present research interests include photoelectric image, image process.

Qiao Jian was born in 1980, and graduated in Ji Lin University, and was associate research fellow in Changchun Institute of Optics, Fine Mechanics 
and Physics, Chinese Academy of Sciences, and is associate research fellow in Foshan University now. Her present research interests include Structure design of fine optical mechanics, Laser precision machining technology and Heavy-duty mobile robot

Zhang Wenbao was born in 1967, and graduated in Qiqi Har University and is associate research fellow in Changchun Institute of Optics, Fine Mechanics and Physics. His main research interests include structure design of fine optical mechanics.

Li Ning was born in 1983, and graduated in Changchun Institute of Optics, Fine Mechanics and Physics, Chinese Academy of Sciences, and is associate research fellow in Changchun Institute of Optics, Fine Mechanics and Physics, Chinese Academy of Sciences now. His present research interests include photoelectric image.

\section{Authors' contributions}

All authors take part in the discussion of the work described in this paper. The author XX wrote the first version of the paper. The author LC carried out the experiments of the paper. QJ, ZW, and LN revised the paper in different versions. All authors read and approved the final version of the manuscript.

\section{Competing interests}

The authors declare that they have no competing interests.

\section{Publisher's Note}

Springer Nature remains neutral with regard to jurisdictional claims in published maps and institutional affiliations.

\section{Author details}

${ }^{1}$ Changchun Institute of Optics, Fine Mechanics and Physics, Chinese Academy of Science, Changchun 130033, Jilin, China. ${ }^{2}$ College of Mechanical Engineering, Foshan University, Foshan, China.

Received: 6 October 2018 Accepted: 7 January 2019

Published online: 15 February 2019

\section{References}

1. S. Hacohen, S. Shoval, N. Shvalbc, Applying probability navigation function in dynamic uncertain environments. Robot. Auton. Syst. 87, 237-246 (2017)

2. S. Herzog, F. Wörgötter, T. Kulvicius, Generation of movements with boundary conditions based on optimal control theory. Robot. Auton. Syst. 94, 1-11 (2017)

3. R. Iraji, S.M. Ghadami, Aids control using state-dependent Riccati equation. Sci. Int. 27, 1183-1188 (2015)

4. Q. Jia, Y. Liu, G. Chen, H. Sun, State-dependent Riccati equation control for motion planning of space manipulator carrying a heavy payload. Open Mech. Eng. J. 9(1), 992-999 (2015)

5. Y.L. Kuo, T.L. Wu, A suboptimal tracking control approach based on the state-dependent Riccati equation method. J. Comput. Theor. Nanosci. 13, 1013-1021 (2016)

6. M. Mendesy, A.P. Coimbray, M.M. Crisostomoy, Assis-cicerone robot with visual obstacle avoidance using a stack of odometric data. IAENG Int. J. Comput. Sci. 45, 219-227 (2018)

7. P.D. H. Nguyen, C.T. Recchiuto, A. Sgorbissa, Real-time path generation and obstacle avoidance for multirotors: A novel approach. J. Intell. Robot. Syst. 89, 27-49 (2018)

8. Ç. Tayfun, in The International Federation of Automatic Control, Statedependent Riccati equation (SDRE) control: a survey (2008), pp. 6-11

9. P.K. Menon, T. Lam, L.S. Crawford, V.H.L. Cheng, in American Control Conference, Real-time computational methods for SDRE nonlinear control of missiles (2002), pp. 1-17

10. M.H. Hurni, P. Sekhavat, I.M. Ross, in AIAA Infotech Aerospace Conference AIAA, Issues on robot optimal motion planning and obstacle avoidance (2009), pp. 1-20

11. S.S. Mohammadi, H. Khaloozade, in 4th international conference on control, Instrumentation, and Automation, Optimal motion planning of unmanned ground vehicle using SDRE controller in the presence of obstacles (2016), pp. 167-171

12. S. Xie, P. Wu, Y. Peng, J. Luo, J. Gu, D. Qu, Q. Li, in Proceeding of the IEEE International Conference on Information and AutomationHailar, The obstacle avoidance planning of USV based on improved artificial potential field (2014), pp. $746-751$
13. J. Slávka, S. Ján, in IEEE 11th International Symposium on Intelligent Systems and Informatics, Application of the state-dependent Riccati equation method in nonlinear control design for inverted pendulum systems (2013), pp. 26-28

14. F. Liccardo, S. Strano, M. Terzo, in World Congress on Engineering, Optimal control using state-dependent Riccati equation (SDRE) for a hydraulic actuator (2013), pp. 3-5

15. S.M.H. Rostami, M. Ghazaani, State dependent Riccati equation tracking control for a two link robot. J. Comput. Theor. Nanosci. 15, 1490-1494 (2018)

16. A. Hamdache, S. Saadi, A stochastic nominal control optimizing the adoptive immunotherapy for cancer using tumor-infiltrating lymphocytes. Int. J. Dynam. Control. 5, 783-798 (2017)

17. V.T. Wang, P.M. Hayes, Synthetic Aperture Sonar Track Registration Using SIFT Image Correspondences[C]. IEEE J. Ocean. Eng. 42(4), 901-913 (2017)

18. S. Jiang, M. Lian, C. Lu, Q. Gu, S. Ruan, X. Xie, Ensemble prediction algorithm of anomaly monitoring based on big data analysis platform of open-pit mine slope. Complexity (2018) doi.org/10.1155/2018/1048756

19. A.M. Yang, X.L. Yang, J.C. Chang, B. Bai, F.B. Kong, Q.B. Ran, Research on a fusion scheme of cellular network and wireless sensor networks for cyber physical social systems. leee Access 6(99), 18786-18794 (2018)

20. K. Sinan, Tracking control of elastic joint parallel robots via state-dependent Riccati equation. Turk. J. Elec. Eng. Comput. Sci. 23, 522-538 (2015)

\section{Submit your manuscript to a SpringerOpen ${ }^{\circ}$ journal and benefit from:}

- Convenient online submission

- Rigorous peer review

- Open access: articles freely available online

High visibility within the field

- Retaining the copyright to your article

Submit your next manuscript at $\boldsymbol{\nabla}$ springeropen.com 